\title{
Produção científica na área da Psicologia referente à temática da morte
}

Scientific production in the field of psychology on death

Producción científica en el área de psicología referente a la temática de la muerte

\author{
Suane Pastoriza Faraj \\ Sabrina Daiana Cúnico ${ }^{* *}$ \\ Alberto Manuel Quintana** \\ Carmem Lúcia Colomé Beck ${ }^{* * * *}$
}

\begin{abstract}
Resumo
Este estudo buscou conhecer o que tem sido publicado pelos profissionais da Psicologia sobre a morte, visando a contribuir para o conhecimento científico e para intervenções adequadas na atuação profissional, uma vez que essa temática está presente no cotidiano profissional do psicólogo. Realizou-se uma revisão sistemática de literatura entre os anos de 2002 e 2012, utilizando-se das bases de dados Scielo e Pepsic, considerando como descritores "Tanatologia", "Psicologia" e "morte". O estudo das informaçōes foi realizado por meio da análise de conteúdo, a partir da qual foram elencadas as categorias "concepçōes sobre a morte", "família e morte", "ensino e morte", "profissionais da saúde e morte", "instituições e morte" e "pulsão de morte". Os resultados apontam certa carência de pesquisas, reforçando a importância de que mais estudos sejam realizados a fim de aprofundar tais compreensōes acerca da temática da morte, sustentando a noção da presença da morte como parte integrante da vida.
\end{abstract}

Palavras-chave: Psicologia. Morte. Tanatologia.

\begin{abstract}
This study aims to understand what has been published by psychology professionals on death, to contribute to scientific knowledge and to intervene appropriately in professional practice, since this is a recurring theme with everyday professional psychologist. We have performed a
\end{abstract}

\footnotetext{
Mestranda do Programa de Pós-graduação em Psicologia da Universidade Federal de Santa Maria (UFSM), psicóloga.

** Mestranda do Programa de Pós-graduação em Psicologia da UFSM, psicóloga. Endereço: Rua Senador Cassiano, 746 Bairro Dores, Santa Maria-RS. CEP: 97050-680. Telefone: (55) 8116-4950. E-mail: sabrinacunico@yahoo.com.br.

*** Professor Dr. do Departamento de Psicologia e do Programa de Pós-graduação em Psicologia da UFSM.

**** Professora Dr. ${ }^{a}$ do Programa de Pós-graduação em Psicologia e do Programa de Pós-Graduação em Enfermagem da UFSM.
} 
systematic review of the literature between 2002 and 2012, by using the Scielo and Pepsic databases considering thanatology, psychology and death as descriptors. An analysis of the data was performed by content analysis, from which we have listed the categories: Conceptions about death, and Family and death, Education and death, Health professionals and death, Institutions and death and Death impulse. The results indicate a certain lack of research, reinforcing the importance that more studies must be conducted to further such understandings about the theme of death, supporting the notion of the presence of death as part of life.

Keywords: Psychology. Death. Thanatology.

\section{Resumen}

Este estudio pretende conocer lo que ha sido publicado sobre la muerte por los profesionales de Psicología, objetivando contribuir para el conocimiento científico y para mejorar las intervenciones del psicólogo, pues esta temática está presente en su trabajo diario. Se realizó una revisión sistemática de la literatura entre los años 2002-2012, en las bases de datos Scielo y Pepsic, considerando como descriptores Tanatología, Psicología y muerte. El análisis de las informaciones fue realizado utilizando el análisis de contenido, a partir del cual se formularon las siguientes categorías: "concepciones sobre la muerte", "familia y muerte", "enseñanza y muerte", "profesionales de la salud y muerte", "instituciones y muerte", y "pulsión de muerte". Los resultados apuntan a cierta carencia de investigaciones, fortaleciendo la importancia de que sean realizados más estudios a fin de profundizar tales comprensiones sobre la temática de la muerte, sustentando la noción de que la muerte es parte integrante de la vida.

Palabras clave: Psicología. Muerte. Tanatología.

\section{Introdução}

psicólogo, desde a legitimação da profissão, vem atuando na área da
saúde, inicialmente no âmbito hospitalar e, posteriormente, em diversos
contextos dosistema de saúde, como ambulatórios, clínicas, universidades,
entre outros. Nesse panorama, entende-se que a temática da morte faz parte
do cotidiano profissional, seja na clínica, no hospital ou nas demais áreas de
atuação. Assim, julga-se de extrema importância o estudo desse assunto, a fim
de contribuir para intervenções adequadas no contexto profissional. 
$\mathrm{Na}$ história da humanidade, há mudanças significativas de paradigmas referentes à morte. Observa-se que, até o século XIX, a morte era considerada algo natural e admissível, tendo assumido, nos séculos subsequentes, um caráter oculto e inaceitável (Hennezel, 2006). Dessa forma, entende-se que os sentidos atribuídos ao processo do morrer sofreram variações de acordo com o momento histórico e os contextos socioculturais, ou seja, o morrer não é apenas um fato biológico, mas sim um processo construído socialmente (Menezes, 2004).

Tal afirmação pode ser amplamente observada no estudo de Ariès (1977). Para o autor, o homem foi, durante muito tempo, o senhor soberano de sua morte e das circunstâncias dela, tendo deixado de sê-lo ao longo dos tempos. $\mathrm{Na}$ Antiguidade, a morte de alguém era quase sempre anunciada, ou seja, o sujeito sabia que ia morrer, seja porque ele próprio atentou a isso, seja porque alguém o advertiu. No entanto, a morte súbita (raridade na época) era muito temida, pois nela não cabia o arrependimento e também privava o homem de sua morte, já que não dava tempo para que ele a presidisse (Ariès, 1977).

Naquela época, da mesma forma que se nascia em público, também se morria em público. A partir do momento em que alguém ficava muito enfermo, seu quarto enchia-se de parentes, filhos, amigos, vizinhos e até desconhecidos. Ou seja, a iminência da morte transformava o quarto do doente em uma espécie de lugar público (Ariès, 1977). O enfermo, por sua vez, chamava um de cada vez: seus pais, familiares e empregados para dizerlhes adeus, pedir perdão e dar-lhes a benção (Ariès, 1977).

O papel do sacerdote e do médico diante do moribundo também sofreram mudanças significativas desde o século XIV. Nessa época, a Igreja impedia que os médicos permanecessem ao lado do doente até a sua morte, delegando sacerdotes para tal função. Isso ocorria devido à crença de que a morte nada mais era do que um desejo de Deus. A partir do século XVIII, com a prevalência do conceito de morte natural, os médicos passaram a ter o direito de permanecer com o doente até seu falecimento. Ou seja, a Igreja passou a permitir a "luta" da Medicina contra a morte (Chiavenato, 1998).

A respeito disso, Zaidhaft (1990) afirma que, até o século XVIII, a morte representava para a Medicina o fim da doença assim como o fim da vida. No entanto, no século XIX, a relação entre morte, vida e doença passou a ser pensada de maneira científica, e a morte se tornou um instrumento que possibilitava ao profissional das ciências médicas aprender sobre a vida e as causas das doenças e mortes. 
A partir do século XVII, o homem deixou de exercer sozinho a soberania de sua própria vida e, consequentemente, da sua própria morte, pois a dividiu com a família. Se, antes, a família era afastada das decisões graves que o enfermo deveria tomar diante da morte, hoje, cada vez mais, é ela que toma as decisões. Além disso, na atualidade, não há mais resquícios, nem da noção da aproximação da morte nem do caráter público e solene que acompanhava esse momento. Ao contrário, o que se observa é um pacto entre família e médico, a fim de dissimular a um doente grave o seu real estado, isto é, o novo costume exige que o doente morra na ignorância de sua morte (Ariès, 1977). De fato, a Medicina moderna tende a deixar em segundo plano o sofrimento psíquico proveniente de uma doença e da possibilidade da morte, não abrindo, muitas vezes, espaços de escuta para que o paciente possa falar sobre a ruptura provocada no momento anterior e no posterior à doença, nem para os danos psicológicos provocados pelo processo do adoecimento (Avellar, 2011). A respeito disso, percebe-se que a forma adotada pelos hospitais para lidar com a morte parece ser colocá-la no lugar da exclusão, isto é, no lugar daquilo que não pode e não deve ser dito (Quintana, Cecim \& Henn, 2002).

De acordo com Menezes (2004), desde o início do século XX, o final da vida e a morte constituem uma área de investigação das ciências sociais. Porém, durante algumas décadas do século XX, são poucas as referências sobre a morte, tendo ela ressurgido mais sistematicamente como tema de estudos a partir da década de 1960, quando os pesquisadores constataram mudanças nas práticas e representações relativas à morte e ao morrer.

$\mathrm{Na}$ primeira metade da década de 1970, pesquisadores das ciências sociais dedicaram-se a refletir sobre a morte, principalmente acerca dos motivos do silêncio em torno dela e do morrer nas sociedades ocidentais. A partir daí, surgiram publicações que denunciavam o ocultamento da morte, inicialmente restringidas ao meio intelectual, sendo depois amplamente divulgadas. Nesse contexto, a exclusão da morte e de quem está morrendo foram citadas como aspectos fundamentais da Modernidade (Menezes, 2004).

Diante disso, considera-se que a eliminação da fala sobre a morte e sobre o processo de morrer tem implicações na forma como os indivíduos sentem e lidam com a morte das pessoas próximas, o que interfere na aceitação de morte do próprio indivíduo. Assim, entende-se ser necessário investigar o que os profissionais da Psicologia estão pesquisando e publicando sobre essa temática, visto ser a morte uma das fases do ciclo de vida do ser humano e, portanto, objeto de estudo da psicologia. 


\section{Método}

A fim de atingir o objetivo proposto, foi realizada uma revisão sistemática, utilizados os descritores "Tanatologia", "Morte" e "Psicologia", em português, nas bases de dados Pepsic (Periódicos de Psicologia) e Scielo (Scientific Eletronic Library On-line). A pesquisa compreendeu o período de 2002 a 2012 e foi realizada entre 4 de maio e 4 de junho de 2012. Os critérios de inclusão foram: artigos brasileiros publicados em português; artigos que versavam sobre a temática da morte não provocada; artigos publicados na íntegra; e artigos que continham ao menos um psicólogo(a) ou estudante de Psicologia entre os autores. Sendo assim, foram excluídos os demais artigos.

Anteriormente à consideração dos critérios de exclusão, foram encontradas 83 publicações brasileiras no Scielo (67 referentes a Psicologia e morte, e 16, à Tanatologia) e 53 no Pepsic (todas encontradas com os descritores Psicologia e morte). Destas, excluindo-se aquelas que não eram escritas por ao menos um profissional da Psicologia, que não estavam expostas na íntegra e que não tratavam da temática da morte não provocada, restaram 51 artigos. Foram encontrados três artigos que se repetiam, sendo um em bases diferentes e dois na mesma base.

Para a análise dos dados, foi utilizada a análise de conteúdo proposta por Bardin (1979), a qual se refere a um conjunto de instrumentos metodológicos aplicados aos discursos, analisando as comunicaçóes, decompondo-as e elencando categorias. Após a leitura dos artigos, ocorreu a reunião e a síntese dos conteúdos e transformação destes em categorias de análise, sendo estas construídas a posteriori, com base nos conteúdos dos artigos, a fim de promover o melhor entendimento sobre os dados obtidos.

Assim, seis categorias foram elencadas: a) concepções sobre a morte: engloba as percepções atribuídas à morte nas diferentes fases do desenvolvimento humano e em diversos contextos socioculturais; b) família e morte: apresenta a temática da morte no contexto familiar, como luto, doação de órgãos e acompanhamento psicológico; c) ensino e morte: engloba estudos que abordam a temática na formação acadêmica bem como estudos que discutem, em diferentes instituições de ensino, a educação para a morte; d) profissionais de saúde e morte: apresenta os estudos que mostram a experiência da morte vivenciada pelos profissionais de saúde; e) instituiçôes de saúde e morte: expóe os estudos que apontam a temática da morte no contexto das instituições de saúde referentes à humanização no atendimento à saúde, cuidados paliativos, hospitalização, entre outros; ef) pulsão de morte: mostra estudos que abordam a temática da pulsão de morte. 


\section{Resultados e discussão}

Na busca pela produção científica na área de Psicologia sobre a temática da morte, encontraram-se 51 artigos que estão em conformidade com os critérios de inclusão estabelecidos. Destes, observou-se que a maior parte tratava de estudos de revisão teórica (22), seguindo de estudos empíricos (19) e relatos de experiência (10).

\section{1) Concepçôes sobre a morte}

Nesta categoria, pretende-se discutir as concepções atribuídas à morte em diferentes contextos e nas diferentes fases do desenvolvimento humano. Foram encontrados nove artigos que versavam sobre tais aspectos.

O estudo de Hohendorff e Melo (2009) apresenta uma revisão teórica a respeito da compreensão da morte nas diferentes fases do desenvolvimento humano. De acordo com os autores, na infância, iniciase a percepção sobre a finitude, entretanto existe uma relação entre o nível de desenvolvimento cognitivo e a compreensão da morte. Assim, crianças até certa idade não compreendem os aspectos centrais da morte. $\mathrm{Na}$ adolescência, apesar de o jovem não pensar sobre a temática, entende e percebe suas características essenciais e o seu significado (Hohendorff \& Melo, 2009).

Rodriguez e Kovács (2005), por meio de um estudo que pretendeu conhecer como os adolescentes percebem e relacionam-se com a morte e como explicam as altas taxas de mortalidade na adolescência, constataram que os adolescentes expressam sentimento de imortalidade e onipotência, não compreendendo a morte como possibilidade pessoal. Esse entendimento difere da idade adulta, em que a possibilidade da morte é concretizada como algo possível de acontecer, apesar de ser temida pelos adultos jovens. Nessa fase, a morte tem um significado social atribuído devido às alterações que causa no contexto familiar e social. $\mathrm{Na}$ velhice, a morte é pensada como algo natural e é mais aceita, uma vez que é vista como a última fase do desenvolvimento humano. Resultados análogos também foram encontrados no estudo de Hohendorff e Melo (2009).

Em estudo semelhante, Barbosa, Melchiori e Neme (2011) buscaram ampliar a compreensão de como pessoas, em diferentes etapas do desenvolvimento, lidam com perdas e com a própria finitude. Os resultados encontrados vão ao encontro dos achados de Rodriguez e 
Kovács (2005) e apontam que os adultos são os que mais demonstram aflição e inquietação frente à sua própria morte e de pessoas próximas. Já os adolescentes a encaram como sendo um acontecimento distante e impessoal, e os idosos se referem a ela com maior proximidade e aceitação.

Seguindo o mesmo viés, há o estudo de Borges, Silva, Toniollo, Mazer, Valle e Santos (2006), que investigam, por meio de uma revisão não sistemática de literatura, quais as percepções da morte e do morrer na perspectiva de pacientes oncológicos em diferentes fases do ciclo vital. Os resultados encontrados demonstram que a percepção da morte vai se modificando conforme o pensamento e a linguagem vão se desenvolvendo. No paciente adulto, a concepção acerca da morte dependerá da experiência física e psicológica pela qual ele está passando. Mais uma vez, identifica-se que, no idoso, a morte é mais bem aceita e que depende, sobretudo, da satisfação atribuída à vida. No entanto, os autores ressaltam que a percepção da morte é, efetivamente, uma experiência individual e que, dessa forma, deve ser considerada por meio da percepção subjetiva de cada paciente oncológico.

Para Soares e Dantas (2006), que desenvolveram um estudo teórico sobre a morte e o morrer na Hipermodernidade, a relação do sujeito "hipermoderno" com a morte oscila entre considerá-la como algo concreto e como "horrível". Segundo os autores, a morte é sentida na Hipermodernidade como uma "traição cometida pela tecnologia". De modo similar, Combinato e Queiroz (2006) fazem uma reflexão sobre os aspectos psicossociais envolvidos na morte, tendo em vista a sensibilização sobre a importância de discutir e refletir sobre essa temática, considerando-a parte do desenvolvimento humano.

Além de tais aspectos, tem-se o artigo teórico de Kind (2011), que traz importantes questionamentos acerca dos embates e definições assumidos pelo conceito de morte cerebral, resgatando parte do processo de sua construção como fato médico. Também há os estudos de Kovács (2003) e Torres (2003), que refletem, respectivamente, um sobre conceitos como eutanásia para diferentes religiões, aspectos legais, distanásia, suicídio assistido, cuidados paliativos; e o outro, sobre os fatores impulsionadores do surgimento da Bioética e questóes básicas, como definição de morte, consentimento livre e informado, as quais são analisadas pela autora como ainda polêmicas e controvertidas.

Diante do exposto, percebe-se que as diferentes concepções atribuídas à morte são um dos focos de estudo de quem trabalha com esse tema. Houve certa semelhança nos resultados encontrados pelas pesquisas qualitativas 
realizadas, que concluem que a concepção sobre a morte sofre variações ao se considerar o diferente estágio de desenvolvimento do sujeito. Além disso, estudos teóricos vêm sendo realizados, a fim de contribuir com as discussões a respeito do entendimento sobre morte cerebral, da bioética no processo de morrer e das perspectivas psicossociais da morte.

\section{2) Família e morte}

Nesta categoria, o processo do luto, o acompanhamento psicológico à família e ao paciente terminal, e a doação de órgãos se destacam como temas desenvolvidos nos artigos analisados que contemplam a família. Foram encontrados 13 artigos que versam sobre tais aspectos.

O estudo de Carvalho (2007), assim como o de Santos, Rosenburg e Buralli (2004) são referentes à perda gestacional. Carvalho (2007) aborda o processo do luto e aponta a importância da presença de familiares ao longo do processo da perda. Por outro lado, o estudo de Gesteira, Barbosa e Endo (2006) focou o luto no processo de aborto provocado, através de um relato de experiência. Os autores apontam que as mulheres em processo de abortamento provocado, que sofreram uma perda, ficam relegadas ao segundo plano. Assim, é necessário que oportunidades sejam criadas para que elas também vivenciem o seu luto.

Os resultados do estudo de Basso e Marin (2010), sobre o comportamento de apego em adultos e a experiência da perda de um ente querido, também apontam que as repercussôes da morte do adulto que conta com um suporte emocional e confiança em familiares e amigos são mais bem elaboradas. É importante destacar que vários os estudos destacam a necessidade e a relevância de uma equipe de saúde capacitada para lidar com questões referentes à morte (Basso \& Marin, 2010; Carvalho, 2007; Santos, Rosenburg \& Buralli, 2004).

Os artigos analisados referentes à morte e luto abordam o tratamento e acompanhamento psicológico a sujeitos que vivem uma situação de perda. Os estudos mostram que o tratamento terapêutico de luto mediante o enfoque da terapia cognitivo-comportamental se mostrou eficaz. Os sintomas de depressão, ansiedade e desesperança foram reduzidos, a melhora da qualidade do sono foi evidenciada, assim como a melhora na qualidade de vida (Silva $\&$ Nardi, 2010, 2011a, 2011b).

O acompanhamento terapêutico à família é abordado pelos estudos como uma prática que auxilia no processo do luto. Isso pode ser observado no estudo de Souza, Wottrich, Seelig, Vigueras, Ruschel (2007) que descrevem 
alguns aspectos da experiência do Serviço de Psicologia Clínica de um hospital, relacionados ao acompanhamento de familiares mediante óbito de crianças internadas em unidades pediátricas.

Sobre tal aspecto, Oliveira, Santos e Mastropietro (2010) realizaram um estudo com base em um acompanhamento psicológico de um paciente com leucemia, que se iniciou no tratamento, seguiu com o diagnóstico de ausência de possibilidades terapêuticas e foi até o momento da sua morte em uma enfermaria. De modo semelhante, Schmidt, Gabarra e Gonçalves (2011) guiaram um estudo que objetivou analisar e refletir sobre a atuação do psicólogo em situações de morte no contexto hospitalar, bem como sobre o processo de terminalidade e despedida para as pessoas enfermas e seus familiares, por meio de um estudo de caso. As autoras concluem que o ritual de despedida constitui-se em vivência possibilitadora de mudanças e resgates das relações familiares, bem como de elaboração do processo de luto, tanto para o sujeito doente e família quanto para a equipe de saúde.

Diante da morte no contexto familiar, a pesquisa de Ferreira, Almeida e Rasera (2008) descreve e analisa os sentidos que casais constroem sobre o câncer de mama da parceira e sobre as formas de se relacionar com esse adoecimento. Os resultados mostraram que os sentidos de provação e morte construídos para o câncer da parceira despertaram nos participantes sentimentos de revolta e ansiedade, e a relação com Deus.

Já no estudo de Anton e Piccinini (2010), que trata do impacto do transplante hepático infantil, os autores identificaram que a relação genitores-criança doente foi permeada pelo medo da morte, levando a atitudes permissivas e superprotetoras, na tentativa de poupar o filho de mais sofrimentos, sendo que esse padrão de relacionamento se manteve presente mesmo após o transplante e a melhora do quadro de saúde dos filhos. Além disso, os resultados apontaram que toda a família foi afetada pela doença infantil, havendo necessidade de reestruturação familiar, o que reforça a importância do acompanhamento psicológico precoce e sistemático às famílias, visando a facilitar a adaptação à situação de doença, prevenindo o desenvolvimento de problemas emocionais.

Outro tema de extrema importância relacionado diretamente à morte no contexto familiar se refere à doação de órgãos. Nesta pesquisa, encontrou-se apenas um artigo sobre o assunto. O estudo de Quintana e Arpini (2009) aponta as representações sobre a doação de órgãos na população leiga, ou seja, com sujeitos que não pertencem à área da saúde. Os resultados mostraram, quanto à doação de órgãos, tanto os fatores que facilitam (confiança na equipe médica, a expressão do desejo da pessoa falecida) como os de resistência 
(dificuldade de aceitação da morte, identificação da morte com a morte clínica, desejo de manutenção da integridade do corpo do falecido). O estudo ressalta a importância de falar sobre a morte com os familiares, amigos e pessoas próximas, assim como a necessidade do atendimento humanizado que transmita confiança à família do paciente nas instituições de saúde.

Diante do exposto, identifica-se que, no que tange ao tema da morte no contexto familiar, este é abordado por diferentes perspectivas. O luto pelo aborto provocado ou não foi um dos assuntos abordados nos artigos, bem como a questão da doação de órgãos e associação da morte com o diagnóstico de câncer e, ou, problemas hepáticos. Além disso, relatos de experiência trouxeram à tona a questão do acompanhamento psicológico com pacientes terminais, a fim de facilitar a elaboração do processo de luto, tanto para o sujeito doente e família quanto para a equipe de saúde.

\section{3) Ensino e morte}

Esta categoria abarca os estudos encontrados que dizem respeito ao estudo da morte relacionada ao ensino. Considera-se relevante tal categoria, já que a temática da morte carece na atualidade de espaço de discussão. Foram encontrados apenas oito artigos que discutem essa questão.

O estudo de Kovács (2008) destaca os autores pioneiros da Tanatologia, como Herman Feifel, Robert Kastenbaum e Elizabeth KüblerRoss. Além disso, aborda os principais temas de estudo na área e discute a formação de profissionais da área de saúde e educação que lidam com pessoas que estão vivendo uma situação de perda e morte.

Nesse contexto, Junqueira e Kovács (2008), por meio de uma pesquisa realizada com acadêmicos de Psicologia, identificaram que o curso de graduação em Psicologia não aborda o tema da morte, sendo que questões referentes à temática não entram no programa de nenhuma disciplina. Os autores acrescentam que o despreparo dos discentes é evidente, pois estes também não abordam a temática, sendo esta discutida apenas de maneira superficial quando algum aluno questiona a respeito.

A graduação em Psicologia é apontada por Díaz e Henriques (2006) como "diretiva e amparada somente por teorias que se sobrepóem às indagações existenciais como, por exemplo, o confronto com a finitude". Junqueira e Kovács (2008) apontam que os acadêmicos de Psicologia não se sentem preparados para lidarem com aspectos referentes à morte, sendo evidente, no curso, a carência de referenciais, discussões e estudos sobre a morte. Salientam a importância da inserção do tema na formação do psicólogo, afirmando que 
a morte faz parte do cotidiano profissional, tanto na escola e hospital quanto na área clínica e organizacional, entre outras.

Os estudos de Brêtas, Oliveira e Yamaguti (2006), e Oliveira, Brêtas e Yamaguti (2007) sobre as representações de estudantes de Enfermagem sobre a morte e o morrer indicam que esses estudantes também carecem de preparo profissional para lidarem com as questóes da morte. Pode-se averiguar que o curso de Enfermagem, assim como o de Psicologia não está preparando de maneira adequada o futuro profissional quanto às questôes referente à morte, sendo evidente a insuficiência de discussões teóricas e práticas na academia. Dessa maneira, percebe-se a necessidade e a importância de repensar a formação acadêmica acerca da preparação do estudante para a atuação profissional, especificamente as que envolvem a temática da morte, com a urgente alteração na formação acadêmica.

Seguindo nesse viés, tem-se o estudo de Kovács (2005), o qual discute possibilidades de educação para a morte tanto para os profissionais de saúde quanto para os leigos, por meio de espaço de discussão nas escolas, hospitais, graduação, assessoria, grupos multidisciplinares, entre outros. $\mathrm{O}$ artigo sinaliza que a educação para a morte é um desafio urgente, principalmente para os profissionais de Saúde e de Educação. França e Botomé (2005), em resenha realizada sobre o livro publicado por Kovács (2003), ressaltam a necessidade de que os profissionais da saúde e da educação tenham uma formação que lhes permita enfrentar o processo de morte com uma melhor preparação para que, de fato, possam contribuir para amenizar o sofrimento diante desse fenômeno.

De acordo com o exposto, pode-se observar a carência de educação para a morte nas instituições de ensino. Tal situação pode ser uma das causas para o evidente despreparo que alguns profissionais da saúde demonstram ao se deparar com situações em que envolvam o processo de morrer. Entende-se que a educação para a morte deve envolver a criação de espaços para o estudo, a reflexão e a discussão da temática, a fim de minimizar os medos e as angústias provenientes da proximidade do fenômeno.

\section{4) Profissionais de saúde e morte}

Esta categoria abarca os estudos que contemplam a relação dos profissionais da saúde com a temática da morte. Foram encontrados cinco artigos que tratam sobre esse tema.

Os profissionais de saúde que são responsáveis pelo cuidado de pacientes portadores de enfermidades potencialmente fatais convivem diretamente com 
a possibilidade da morte destes. O estudo realizado com médicos, enfermeiros, fonoaudiólogos e fisioterapeutas, a fim de compreender a subjetividade dos profissionais de saúde, seu funcionamento egoico e os mecanismos de defesa utilizados no contexto hospitalar mostra que estes apresentam dificuldades para compreender e enfrentar a morte e a finitude, mesmo conseguindo se restabelecer adaptativamente, mantendo a integridade egoica para a realização de suas funções. Os profissionais, devido às dificuldades de enfrentamento do sofrimento e morte, os quais estão presentes no setting que trabalham, fazem uso de alguns mecanismos de defesa, entre eles a sublimação e a negação (Medeiros \& Pinto Junior, 2006).

A necessidade de um espaço de manifestação de angústias e temores para os profissionais de saúde, a fim de beneficiar tanto o profissional quanto o paciente, é destacada no estudo de Medeiros e Pinto Junior (2006), sendo que esse "espaço" poderia ser viabilizado por um trabalho de escuta analítica ou de análise institucional. Staniscia, Pereira, Guimarães, Mekler e Rezende (2011) também sinalizam a importância e a necessidade de um espaço de reflexão para os profissionais da saúde, mais especificamente para os médicos, pois parece que o sofrimento vivenciado por estes não é trabalhado de maneira sistemática e não se pode dizer que existem formas de enfrentamento favorável adotadas por esses profissionais ao lidarem com suas dificuldades, visto que as reflexões sobre essas questôes são insuficientes.

Medeiros e Lustosa (2011) fazem uma reflexão teórica a respeito das possibilidades de ajuda à família no momento da comunicação do óbito e a dificuldade dos profissionais em falar sobre a temática da morte, ressaltando o trabalho do psicólogo hospitalar. O estudo considera a necessidade de pesquisar sobre os profissionais e suas dificuldades de falar sobre a morte. Destaca a oferta de atenção aos profissionais de saúde, incluindo os psicólogos hospitalares, por meio de um atendimento psicoterápico, pois, assim, torna possível o atendimento humanizado ao paciente e à família.

O grupo de apoio psicológico inserido no contexto hospitalar também foi abordado nos artigos analisados. De acordo com Santos (2003), que apresenta a experiência de atenção psicológica para a equipe de enfermagem onco-hematológica, o grupo psicológico ofertado para os profissionais de Enfermagem é efetivo para questôes relacionadas ao estresse ocupacional, pois possibilita a troca de experiência, o compartilhamento de emoções, assim como o sentimento de compreensão e acolhimento.

Considerando tais questôes, o estudo de Elias, Giglio, Pimenta e El-Dash (2007) trata de uma experiência de um programa de treinamento sobre a 
intervenção terapêutica para pacientes graves, denominada Relaxamento, Imagens Mentais e Espiritualidade (RIME). O programa de treinamento proposto se mostrou- eficaz para preparar profissionais de saúde para o uso da intervenção RIME, capacitando-os para o processo de cuidar e prestar assistência espiritual segundo uma perspectiva acadêmica. Os resultados sugeriram que o RIME favoreceu a re-significação da dor espiritual de pacientes terminais.

A análise dos estudos que tratam da relação entre os profissionais da saúde e a morte demonstrou que tais profissionais apresentam dificuldades para compreender e enfrentar a morte e, consequentemente, a sua própria finitude. No entanto, evidenciam-se poucos estudos que versam sobre esses aspectos, o que faz pensar que o tema da morte é pouco explorado, tornando difícil para o profissional o atendimento humanizado ao paciente e à família, por não se saber como lidar com a morte e o processo de morrer.

\section{5) Instituições de saúde e morte}

Essa categoria contempla os artigos relacionados a instituições de saúde e morte, tendo sido encontrados dez artigos que contemplavam esse tema.

A humanização na assistência ao atendimento a pacientes hospitalizados é mencionada em alguns estudos. Calvetti, Silva e Gauer (2008) discutem aspectos relacionados à humanização na assistência da criança hospitalizada na unidade de tratamento intensivo. Os autores apontam que o cuidado humanizado ainda precisa ser desenvolvido pela equipe na atenção à saúde da criança restrita ao leito. Salientam ainda que a importância dos profissionais de saúde que atuam em instituiçôes hospitalares estarem voltados para o cuidado da saúde do pacientes e estarem preparados para lidarem com o processo saúde-doença, assim como nascimento e morte.

A humanização ao atendimento também é mencionada no estudo de Porto e Lustosa (2010), que aborda os cuidados paliativos e a Psicologia hospitalar. Para os autores, os cuidados paliativos têm uma nova forma de gestão da morte que assegura, por meio de uma equipe multiprofissional, a necessidade do doente. A Psicologia hospitalar é apontada como uma modalidade pedagógica que tem como grande desafio possibilitar ao paciente uma vida com mais qualidade diante da própria morte. Assim, é apontada a necessidade da atuação de psicólogos nas equipes em cuidados paliativos nas instituições de saúde, uma vez que essa atuação possibilita facilitar o processo de cuidar paliativamente que tem como foco a "qualidade de vida na morte" (Porto $\&$ Lustosa, 2010). 
O tema dos cuidados paliativos também apareceu na revisão proposta por Moritz et al. (2008). Os autores avaliaram o estado atual do conhecimento sobre doença terminal e cuidados paliativos em unidade de terapia intensiva. As conclusōes apontam que os profissionais que atuam nessas unidades e estão envolvidos com o tratamento desses pacientes são submetidos a grande estresse e tensão, sendo desejável que lhes sejam disponíveis programas de educação continuados sobre cuidados paliativos.

Seguindo com o tema da unidade de terapia intensiva, tem-se o estudo de revisão bibliográfica de Borges, Genaro e Monteiro (2010), que trata sobre a entrada de crianças na UTI para visitar entes hospitalizados. A fim de conseguir um melhor entendimento sobre o tema, as autoras fundamentam o artigo com o estudo das fases do desenvolvimento cognitivo e emocional da criança em relação à compreensão da morte para, em seguida, sugerir proposta para rotina de entrada de crianças em unidade de terapia intensiva adulta.

Além dos aspectos já mencionados, encontraram-se também estudos que buscam compreender a experiência da pessoa que vivencia um diagnóstico de câncer, AIDS e, consequentemente, uma situação de hospitalização. Pesquisas apontam que a experiência de um diagnóstico de doenças potencialmente fatais está associada ao medo da morte, assim como busca pelo tratamento e alterações no projeto de vida (Coutinho \& Trindade, 2006; Moreira, Mesquita \& Melo, 2010; Pinto \& Gioia-Martins, 2006; Silva, 2005). É importante mencionar que o estudo de Moreira, Mesquita e Melo (2010) referente à hospitalização mostram que sofrimento, isolamento, diferentes formas de enfrentamento do diagnóstico, assim como a perspectiva da morte são vivenciados pelo paciente no processo de hospitalização.

A respeito da comunicação sobre a morte em instituições de saúde, encontrou-se o artigo de Kovács (2011), que teve por um de seus objetivos verificar como se dá essa comunicação em instituiçôes de saúde e residenciais para idosos. Os resultados encontrados mostram que cabe ao médico e não à equipe falar sobre a morte com pacientes e familiares. Os médicos não se sentem preparados para abordar o tema da morte, que é visto como tarefa de ninguém, já que é função de profissionais de saúde manter a vida. Nas instituições para idosos, o tema é interdito, uma vez que os profissionais afirmam que não é sua função falar sobre a morte com idosos porque esse assunto causa sofrimento.

Pensando nessas questões e a fim de compartilhar um serviço de prontoatendimento psicológico às pessoas que vivenciam uma perda significativa, 
Souza, Moura e Corrêa (2009) discutem os resultados de um serviço dessa especificidade em um hospital público universitário. Os resultados apontaram para a importância da oferta desse serviço que foi demandado tanto por aqueles que vivenciam o luto pela perda de saúde ou pela morte de uma pessoa significativa como por profissionais que trabalham nesse contexto.

Nessa categoria, artigos relacionados ao tema das instituições de saúde e morte foram analisados. A experiência da pessoa que vivencia um diagnóstico de câncer, AIDS e consequentemente uma situação de hospitalização foram alguns dos assuntos abordados pelos estudos. Ademais, a humanização do atendimento e os benefícios dos cuidados paliativos merecem destaque, uma vez que o cuidado humanizado ainda precisa ser desenvolvido pelas equipes multidisciplinares que atuam nesse contexto.

\section{6) Pulsão de morte}

A pulsão de morte, conceito da teoria de Freud, está entre os temas de estudo dos profissionais da área da Psicologia.

Foram encontrados seis artigos que versaram sobre esse conceito. Metzger e Silva Junior (2010) discutem alguns efeitos da pulsão de morte desfusionada. Dias (2006) pesquisa sobre a teoria do sintoma na obra de Freud e a releitura realizada por Lacan pelo viés do "inconsciente estruturado" (na dimensão do simbólico) e do "inconsciente pulsional" (na dimensão do real), apontando o "sintoma-metáfora" e o "sintoma-letra de gozo". Reino e Endo (2011) examinam a noção do narcisismo das pequenas diferenças em Freud acompanhando pari passu a origem, a entrada e as torções do narcisismo das pequenas diferenças em diferentes momentos do pensamento freudiano.

O conceito de pulsão de morte também é visto nos estudos de Naffah Neto $(2005,2007)$ e no de Birman (2010). Este último apresenta um comentário do ensaio de Derrida "États d'âme de la psychanalyse", visando a destacar os conceitos de crueldade e soberania em suas relaçôes com o discurso psicanalítico (Birman, 2010). Enquanto o primeiro aborda que o conceito de experiência da psicanálise Winnicottiana constitui uma espécie de eixo, discutindo as mudanças que tal eixo provoca nos conceitos de sexualidade e de pulsão de morte (Naffah Neto, 2005, 2007). Diante da analise, pôdese constatar que os estudos acerca do conceito de pulsão de morte na área da Psicologia são diversificados, mas estes sinalizam a importância desse conceito na teoria psicanalítica. Isso porque o conceito de pulsão de morte 
possibilitou um novo entendimento acerca dos registros inconscientes e, dessa forma, impulsionou novos estudos sobre o psiquismo humano.

\section{Considerações finais}

Considera-se a morte e seu contexto um fenômeno universalmente pensado e sentido por todos os seres humanos. Porém, ainda que seja um acontecimento natural e que faça parte da vida dos indivíduos, falar sobre morte na atualidade causa certo estranhamento e produz angústia, tanto na área profissional como na pessoal. $\mathrm{O}$ conhecimento científico da Psicologia, especificamente na área da saúde, é amplo e abrange diversas temáticas, sendo a morte uma delas. Entretanto, com a realização deste estudo, pôde-se averiguar certa carência de estudos realizados pelos profissionais da Psicologia acerca da morte e do processo de morrer, uma vez que, no período de dez anos, encontraram-se apenas 51 artigos que abordam tais aspectos.

Ademais, poucos estudos foram encontrados a respeito de como a temática da morte e abordada em cursos de graduação. No entanto, considerase extremamente importante que mais pesquisas com esse enfoque sejam realizadas, a fim de contribuir com as alterações nos currículos acadêmicos, já que se entende que a morte faz parte da vida dos indivíduos e, sendo assim, deve ser falada e discutida. Tal discussão é importante, em especial, para aprimorar a capacitação dos profissionais que estão envolvidos diretamente com a temática.

Esta pesquisa apontou, ainda, que diversos assuntos relacionados à morte estão sendo discutidos, entre eles: o luto, o atendimento psicológico à família e ao paciente terminal, os cuidados paliativos e a doação de órgãos. Destacamse os estudos empíricos e os de caso realizados sobre tais temas, visto que contribuem para o fortalecimento da prática e para a área da saúde.

Ressalta-se também que a maioria das pesquisas encontradas tem por autores pelo menos um profissional e, ou, estudante de outra área do conhecimento, juntamente com os estudantes e, ou, profissionais da Psicologia. Considerando que a interdisciplinaridade é extremamente importante e necessária na área da saúde, entende-se que a relevância desse dado está em estimular que o fenômeno saúde-doença-morte seja pensado de maneira integral, não de forma fragmentada, a fim de compreender o ser humano de forma global, considerando o seu contexto. Por fim, adverte-se para a importância de que mais estudos sejam realizados e que aprofundem diferentes compreensões acerca da temática da morte, sustentando a noção da presença da morte como parte integrante da vida. 


\section{Referências}

Anton, M. C. \& Piccinini, C. A. (2010). O impacto do transplante hepático infantil na dinâmica familiar. Psicologia: Reflexão \& Crítica, 23 (2), 187-197.

Ariès, P. (1977). História da morte no Ocidente: da Idade Média aos nossos dias (P. V. Siqueira, trad.). Rio de Janeiro: Francisco Alves.

Avellar, L. Z. (2011). Atuação do psicólogo nos hospitais da Grande Vitória/ ES: uma descrição. Psicologia em Estudo, 16 (3), 491-502.

Barbosa, C. G., Melchiori, L. E. \& Neme, C. M. B. (2011). O significado da morte para adolescentes, adultos e idosos. Paidéia, 21 (49), 175-185.

Bardin, L. (1979). Análise de conteúdo. (L. A. Reto \& A. Pinheiro, trad.). Lisboa: Edições 70.

Basso, L. A. \& Marin, A. H. (2010). Comportamento de apego em adultos e a experiência da perda de um ente querido. Aletheia, (32), 92-103.

Birman, J. (2010). Crueldade e psicanálise: uma leitura de Derrida sobre o saber sem álibi. Natureza Humana, 12 (1), 1-29.

Borges, K. M. K., Genaro, L. T. \& Monteiro, M. C. (2010). Visita de crianças em unidade de terapia intensiva. Revista Brasileira de Terapia Intensiva, 22 (3), 300-304.

Borges, A. D. V. S., Silva, E. F., Mazer, S. M., Toniollo, P. B., Valle, E. R. M. \& Santos, M. A. (2006). Percepção da morte pelo paciente oncológico ao longo do desenvolvimento. Psicologia em Estudo, 11 (2), 361-369.

Brêtas, J. R. S., Oliveira, J. R. \& Yamaguti, L. (2006). Reflexões de estudantes de enfermagem sobre morte e o morrer. Revista da Escola da Enfermagem da USP, 40 (4), 477-483.

Calvetti, P. Ü., Silva, L. M. \& Gauer, G. J. C. (2008). Psicologia da saúde e criança hospitalizada. Psic, 9 (2), 229-234.

Carvalho, F. T. (2007). Perda gestacional tardia: aspectos a serem enfrentados por mulheres e conduta profissional frente a essas situações. Boletim de Psicologia, 57 (126), 33-48.

Chiavenato, J. J. (1998). A morte: uma abordagem sociocultural. São Paulo: Moderna. 
Combinato, D. S. \& Queiroz, M. S. (2006). Morte: uma visão psicossocial. Estudos de Psicologia, 11 (2), 209-216.

Coutinho, B. B. \& Trindade, Z. A. (2006). As representações sociais de saúde no tratamento da leucemia e linfoma. Psic, 7 (1), 9-18.

Dias, M. G. L. (2006). O sintoma: de Freud a Lacan. Psicologia em Estudo, 11 (2), 399-405.

Díaz, J. R. \& Henriques, O. W. M. (2006). Vida-morte numa equipe de enfermaria: "supervisão da supervisão". Vinculo, 3 (3), 79-90.

Elias, A. C. A., Giglio, J. S., Pimenta, C. A. M. \& El-Dash, L. G. (2007). Programa de treinamento sobre a intervenção terapêutica "relaxamento, imagens mentais e espiritualidade" (RIME) para re-significar a dor espiritual de pacientes terminais. Revista de Psiquiatria Clínica, 34 (Suppl. 1), 60-72.

Ferreira, C. B., Almeida, A. M. \& Rasera, E. F. (2008). Sentidos do diagnóstico por câncer de mama feminino para casais que o vivenciaram. Interface, 12 (27), 863-871.

França, M. D. \& Botomé, S. P. (2005). É possível uma educação para morte? Psicologia em Estudo, 10 (3), 547-548.

Gesteira, S. M. A., Barbosa, V. L. \& Endo, P. C. (2006). O luto no processo de aborto provocado. Acta Paulista de Enfermagem, 19 (4), 462-467.

Hennezel. M. (2006). Morrer de olhos abertos. Portugal: Casa das Letras.

Hohendorff, J. V. \& Melo, W. V. (2009). Compreensão da morte e desenvolvimento humano: contribuições à psicologia hospitalar. Estudos e pesquisas em Psicologia, 9 (2), 480-492.

Junqueira, M. H, R. \& Kovács, M. J. (2008). Alunos de Psicologia e a educação para a morte. Psicologia ciência e profissão, 28 (3), 506-519.

Kind, L. (2011). Intermitências da morte: redefinições do ser humano na difusão da morte cerebral como fato médico. Scientiae Studia, 9 (1), 71-104.

Kovács, M. J. (2003). Bioética nas questões da vida e da morte. Psicologia: USP, 14 (2), 115-167.

Kovács, M. J. (2005). Educação para a morte. Psicologia ciência e profissão, 25 (3), 484-497. 
Kovács, M. J. (2008). Desenvolvimento da Tanatologia: estudos sobre a morte e o morrer. Paidéia, 18 (41), 457-468.

Kovács, M. J. (2011). Instituiçôes de saúde e a morte: do interdito à comunicação. Psicologia: Ciência e Profissão, 31 (3), 482-503.

Medeiros, D. \& Pinto Junior, A. A. (2006). Um estudo sobre a estruturação egoica de profissionais hospitalares por meio do questionário desiderativo. Revista da Sociedade Brasileira de Psicologia Hospitalar, 9 (1), 91-99.

Medeiros, L. A. \& Lustosa, M. A. (2011). A difícil tarefa de falar sobre morte no hospital. Revista da Sociedade Brasileira de Psicologia Hospitalar, 14 (2), 203-227.

Menezes, R. A. (2004). Em busca da boa morte: antropologia dos cuidados paliativos. Rio de Janeiro: Garamond.

Metzger, C. \& Silva Junior, N. (2010). Sublimação e pulsão de morte: a desfusão pulsional. Psicologia USP, 21 (3), 567-583.

Moreira, V., Mesquita, S. \& Melo, A. K. (2010). A experiência de hospitalização vivida por pacientes com Aids. Boletim de Psicologia, 60 (133), 153-166.

Moritz, R. D., Lago, P. M., Souza, R. P., Silva, N. B., Meneses, F. A., Othero, J. C. et al. (2008). Terminalidade e cuidados paliativos na unidade de terapia intensiva. Revista Brasileira de Terapia Intensiva, 20 (4), 422-428.

Naffah Neto, A. (2005). Winnicott: uma psicanálise da experiência humana em seu devir próprio. Natureza Humana, 7 (2), 433-454.

Naffah Neto, A, N. (2007). A noção de experiência no pensamento de Winnicott como conceito diferencial na história da psicanálise. Natureza Humana, 9 (2), 221-242.

Oliveira, J. R., Brêtas, J. R. S. \& Yamaguti, L. (2007). A morte e o morrer segundo representaçóes de estudantes de Enfermagem. Revista da Escola da Enfermagem da USP, 41 (3), 386-394.

Oliveira, E. A., Santos, M. A. \& Mastropietro, A. P. (2010). Apoio psicológico na terminalidade: ensinamentos para a vida. Psicologia em Estudo, 15 (2), 235 244.

Pinto, A. C. \& Gioia-Martins, D. F. (2006). Qualidade de vida subsequente à mastectomia: subsídios para intervenção psicológica. Revista da Sociedade Brasileira de Psicologia Hospitalar, 9 (2), 3-27. 
Porto, G. \& Lustosa, M. A. (2010). Psicologia hospitalar e cuidados paliativos. Revista da Sociedade Brasileira de Psicologia Hospitalar, 13 (1), 76-93.

Quintana, A. M. \& Arpini, D. M. (2009). Doação de órgãos: possíveis elementos de resistência e aceitação. Boletim de Psicologia, 59 (130), 91-102.

Quintana, A. M., Cecim, P. S. \& Henn, C. G. (2002). O preparo para lidar com a morte na formação do profissional de Medicina. Revista Brasileira de Educação Médica, 26 (3), 204-210.

Reino, L. M. G. \& Endo, P. C. (2011). Três versões do narcisismo das pequenas diferenças em Freud. Trivum, 3 (2), 16-27.

Rodriguez, C. F. \& Kovács, M. J. (2005). O que os jovens têm a dizer sobre as altas taxas de mortalidade na adolescência? Imaginário, 11 (11), 111-136.

Santos, A. L. D., Rosenburg, C. P. \& Buralli, K. O. (2004). História de perdas fetais contadas por mulheres: estudo de análise qualitativa. Revista Saúde Pública, 38 (2), 268-276.

Santos, M. A. (2003). Perto da dor do outro, cortejando a própria insanidade: o profissional de saúde e a morte. Revista da Sociedade de Psicoterapias Analíticas Grupais do Estado de São Paulo, 4 (4), 43-51.

Schmidt, B., Gabarra, L. M. \& Gonçalves, J. R. (2011). Intervenção psicológica em terminalidade e morte: relato de experiência. Paidéia, 21 (50), 423-430.

Silva, A. C. O. \& Nardi, A. E. (2010). Luto pela morte de um filho: utilização de um protocolo de terapia cognitivo-comportamental. Revista Psiquiatria Rio Grande do Sul, 32 (3), 113-116.

Silva, A. C. O. \& Nardi, A. E. (2011a). Terapia cognitivista-comportamental para perda gestacional: resultados da utilização de um protocolo terapêutico para luto. Revista de Psiquiatria Clínica, 38 (3), 122-124.

Silva, A. C. O. \& Nardi, A. E. (2011b). Terapia cognitivo-comportamental para luto pela morte súbita de cônjuge. Revista de Psiquiatria Clínica, 38 (5), 213-215.

Silva, L. C. (2005). Vozes que contam a experiência de viver com câncer. Psicologia Hospitalar, 3 (1), 1-17. 
Soares, J. C. \& Dantas, M. A. (2006). Considerações sobre a morte e o morrer na hipermodernidade. Estudos e Pesquisas em Psicologia, 6 (2), 89-104.

Souza, A. L., Wottrich, S. H., Seelig, C., Vigueras, E. S. R. \& Ruschel, P. P. (2007). O acompanhamento psicológico a óbitos em unidade pediátrica. Revista da Sociedade Brasileira de Psicologia Hospitalar, 10 (1), 151-160.

Souza, A. M., Moura, D. S. C. \& Corrêa, V. A. C. (2009). Implicações do pronto-atendimento psicológico de emergência aos que vivenciam perdas significativas. Psicologia Ciência e Profissão, 29 (3), 534-543.

Staniscia, A. C. M., Pereira, L., Guimarães, C. P. A., Mekler, P. L. \& Rezende, F. (2011). Dificuldades emocionais vivenciadas pelos médicos intensivistas da unidade de terapia - adulto de um hospital geral privado. Revista da Sociedade Brasileira de Psicologia Hospitalar, 14 (1), 41-73.

Torres, W. C. (2003). A Bioética e a psicologia da saúde: reflexões sobre questões de vida e morte. Psicologia: Reflexão \& Crítica, 16 (3), 475-482.

Zaidhaft, S. (1990). Morte e formação médica. Rio de Janeiro: Francisco Alves. 